\title{
The Change in the Automotive Industry \\ - A Comparison Between Europe, USA, \\ Japan
}

\section{Prof. Dr.-Ing. H. Schulz}

Technical University of Darmstadt,

Petersenstr. 30, D-64 287 Darmstadt, Germany

Keywords: Automotive industry in Europe, USA, Japan

\section{ABSTRACT}

There are differences in the automotive industry of Europe, USA and Japan. Based on a study, made by PTW and McKinsey, these differences are pointed out and the fields of weakness and strength are shown. 


\section{PRODUÇÃO}

\section{Introduction}

The basis of this paper is an empiric study conducted from 1992 to 1994 by the Institute for Production Engineering and Machine Tools (PTW) of the Darmstadt Technical University, Germany, in cooperation with McKinsey and Comp. In the scope of this study, a total of 167 automotive suppliers were examined worldwide, with the objective of identifying ,top performance in quality management".

The essential reason for the Japanese superiority is that the Japanese above all have excellent control over the quality of their production processes. Outstanding fulfilment of predetermined specifications results in reject and rework rates which are by approx. $50 \%$ better as compared with companies in the other triad regions. Reject rates from customers even are better by several orders of magnitude.

Considering the European and American companies achieving top performance in quality management, it turns out that these companies are primarily leading in the field of ,design quality". They are capable of differentiating clearly from competitors by providing the final customer or the automobile manufacturer an additional benefit when using their products.

Notably they equip their products with supplementary qualities which offer car users a maximum of comfort. In first place the so-called „NVH functions“" are to be mentioned here, i.e. production specifications protecting the passenger cabin from Noise, Vibrations and Harshness. For this final customer focus and the product superiority resulting from it, European and American top companies consider substantial R\&D expenditures to be worthwhile: The Germans for instance spend $5 \%$ of sales on R\&D, the Americans as much as $4.5 \%$. For Japanese companies, the corresponding figure is $3.8 \%$, but their expenditures are oriented less at the final customer but rather more at the automobile manufacturer.

\section{Condition for Learning From the Others: Understanding the Differences of Industrial Structure Between the Triad Regions}

For taking over the others' strengths and eliminating one's own weaknesses, it is in first place of interest to understand why the strengths typical for each region have evolved. This is because only the understanding of reasons and backgrounds can allow to come to reliable statements as to the transferability of the quality management approaches behind these strenghts:

The respective industrial structure (Fig. 1) is responsible for developing these strengths. 
In Japan, the automotive scenery is characterized by the so-called ,keiretsu“. These are enterprise communities of automobile manufacturers and their direct suppliers (,1st tier suppliers"). These direct suppliers make supplies exclusively to a single manufacturer with whom they are generally connected both in capital and frequently also in corporate respects and with whom they cooperate in all questions of management. For this reason it is less important for the supplier to maintain his position in the market against other competitors, but rather to fulfil as perfectly as possible the demands of his customer as to further processing of the product supplied. The key success factor of such a supplier therefore is "design to process" for the automobile manufacturer involved, while it is the automobile manufacturer who takes care of satisfying the demands of the final customer, i.e. the automobile purchaser.

In Europe, where the automotive industries largely have national character, most of the suppliers are constituted by industrial divisions of large-size concerns as well as by medium-size independent companies. Typically, these suppliers have 6 to 15 automobile manufacturers as their customers to be solicited in free competition with other suppliers. This is why it is important for European suppliers to offer in their products some superior benefit for the final customer in order to achieve differentiation from competitors.

In the USA, the „big three“ automobile manufacturers traditionally have a much greater manufacturing depth than is common in Europe or even in Japan. Combined with a strategy of short-term financial optimization, manifesting itself in tough price negotiations and frequent changes of suppliers, this results in a very unsteady relationship between suppliers and automobile manufacturers. However, since recently these „big three" have been adapting their strategy to that used by Europeans, so that for American suppliers similar success factors are emerging as in Europe.

\subsection{Japan: The Keiretsu Becoming Weaker}

The keiretsu system which is considered to have been the major success factor of Japan's automotive industry is currently subject to extreme rationalization and restructuration pressure. The main reason for this is the slow growth of the Japanese automotive industry during the recent years, which is fatal for the strongly growth-based system of keiretsu. Consequentially, the pressure for change will in Japan certainly bring about more competition (beyond the keiretsu) and thus a stronger final customer focus among suppliers as well as to an adjustment of the partially very crowded supplier scene.

\subsection{Europe: A Structural Change Developing}

In recent years, the European automobile manufacturers had a dramatic cost disadvantage as against their 


\section{PRODUÇÃO}

Japanese and American competitors: not rarely up to $30-50 \%$. Since half and up to two thirds of the value addition on an automobile are contributed by suppliers, the automobile manufacturers at first reacted with a drastically increased price pressure on their suppliers. Although this has produced first successful results, future efforts must reach substantially farther. A first approach to cost reductions can consist in the simple relocation of manufacturing steps onto suppliers, since these mostly have a cost structure advantage.

However, still more important than the simple relocation of manuacturing operations is to widen the degree of freedom for the suppliers who must be given the competence for developing and manufacturing modules so as to accomplish quantum leaps. The savings potential of such „modular sourcing“ can be estimated at more than $30 \%$ as complexity costs can be saved on both sides, the supplier can be allowed to "design to process", and transaction costs can be saved due to a reduction of the demand for coordination.

Analysing the manner in which the restructuration currently evolves in Europe, it becomes evident that in particular the large-size concerns are attempting to gain a strategic position in the suppliers market by means of mergers and acquisitions. Especially in Germany it appears that for mergers and take-overs in the automotive supplier industry between 1989 und 1992 the driving force in one third of these instances was access to specific market segments, while in one fifth each of the cases the intention was to establish first-time presence in the automotive sector or to achieve the mass critical for development and manufacturing. In contrast with this, technology acquisition or cost structure enhancement by means of involvement in low labour cost countries played a minor role only.

Consequentially, this means that in Europe the repositioning process in the supplier business is in full swing, but not all desired strategic positions have yet been secured so that strong movements in the market must also be anticipated in the forthcoming years.

\subsection{USA: Productivity and Technological Competence Growing}

The American suppliers are increasing their productivity at an extent as does no other supplier group in the triad (Fig. 2): With an increase rate of approx. $10 \%$ p.a. they are far ahead of the Japanese with approx. $7 \%$ p.a. and the Europeans lagging behind with approx. $4 \%$ p.a. But it is not only through KAIZEN activities used to combat waste of any type that the American companies accomplish these improvement rates, but in particular also by means of a consequent group organization and of an objective-based management.

In the USA and also in Europe, it is primarily the cost and quality position that 


\section{PRODUÇÃO}

will become the decisive knock-out criterion for survival in the market within the restructuration of the automotive (supplier) industry.

\section{Backlog Demand}

\subsection{Japan: Final Customer Competence}

For the development of products with superior final customer benefit, however, Japanese supplier firms will at first have to build up appropriate technology and design competence, because the strong concentration on automobile manufacturers has until now barred their view of automobile users. According to the findings of our study, the Japanese suppliers have between 1991 and 1994 increased their R\&D budgets by $40 \%$ (Fig. 3). However, these efforts are subject to pressure from shrinking profits on sales.

Also, the Japanese try to put greater focus on pre-developments in order to convert the basic final customer and technology trends into basic concepts on which one or more families of series products can be founded. In international comparison, today, their pre-development expenditures amounting to $11 \%$ of the total R\&D working expenditures are still distinctly behind Europe with $15 \%$ and the USA with $17 \%$.

\subsection{USA: Achieving Better Process Quality}

Due to continuously rising customer requirements, the Europeans and Americans will have to learn as fast as possible the Japanese strength of accomplishing excellent process quality, if they want to maintain competitiveness (Fig. 4).

It becomes apparent, that between the leading Japanese and the "rest of the world" there is on one hand a dramatic difference in performance, but that on the other hand the existing gap is dynamic, i.e. the Japanese do not only currently work on a better level but they also make improvements faster than their competitors. The KAIZEN process of continuous improvement is responsible for the superiority of the Japanese in process quality. In addition to this, the Japanese also try to accomplish improvements beyond the system limits of their own companies by including customers and suppliers intensely into their optimization strategies. Finally, the Japanese pursue a consequent strategy of „design to process" which contributes to securing the producibility potential of their products already during the development stage, i.e. preventively.

In Japan, almost four out of five production staff members are involved in KAIZEN activities - almost three times as many as in the USA or Europe. The number of improvement proposals in 


\section{PRODUÇÃO}

Japan exceeds the comparable figures for Western companies by a factor of . Consequentially, this means that Japanese companies take their production increases half from quality team activities (i.e. quasi „bottom-up") and half from activities of indirect areas such as industrial engineering or from production planning (i.e. „top-down"), while European companies virtually exclusively rely on the top-down approach to drive their improvement processes (but without obtaining better results than the Japanese with their proposals from indirect areas).

In summary, it can therefore be said that Western companies only make use inadequately of their most important resource, the workers. While the Japanese have maintained an improvement culture for decades already, putting up not only output targets but consistently also improvement targets for their employees and thus stimulating them to contribute their thinking, many Western companies still consider their workers to be purely executive organs unable of introducing contributions to problem solutions. Although there has recently been a change of trend in this respect, the distance that Europeans and Americans will have to cover in this direction still is long, because management will have to rethink in the first place.

In Japan, suppliers are chosen above all by know-how and not primarily by price aspects: In an ex-ante supplier evaluation, it is notably the product and process know-how that is considered rather than the current cost position. If a supplier meets the requirements, a firm cooperation will be agreed already during the stage of product concept development (i.e. much earlier than in the West). In the scope of this cooperation, the supplier will in most cases be ordered to make a „black-box development", i.e. apart from relevant information about interfaces he will be given as few restrictive product specifications as possible so as to permit him to bring his product know-how to bear fully. In the course of the further development process, target costing as well as joint value analyses will be used to settle cost problems. In the West, by contrast, „blueprint suppliers" still are frequently employed, i.e. extended work benches without genuine improvement potential, chosen purely under cost aspects.

In particular, projects for quality improvement, i.e. projects for production optimization, for improvement of product quality as well as for introduction and application training for quality assurance instruments, are operated by Japanese companies in cooperation with their suppliers at substantially higher intensity than it is done in the West. But also, joint development teams are better equipped with personnel resources (Fig. 5).

Figure 6 shows that Japanese suppliers invest almost three times as much time per customer in simultaneous engineering projects as is usual for Western companies. When the products are in series production, approx. 5 times more time is 
spent on joint continuous improvement activities than is done in Europe or USA. Although this cooperation intensity binds resources to quite a considerable extent, it also brings forth distinct advantages: Above all the close adjustment in development makes the supplied parts reach the agreed quality level earlier, i.e. pre-production modifications can be reduced considerably. Subsequently, optimization in small steps is applied to achieve excellent reject rates, in order to create as little disturbance as possible in the production and assembly process of the automobile manufacturer due to defective bought-in parts supplied on a just-in-time basis.

In Japan, the cooperation is strongly oriented at a know-how transfer between the partners in value addition. For this purpose, residential engineers of the suppliers are for once installed at a customer with their task as an integral part of the customer's development team being to introduce on site the supplier's experience into the manufacturer's new products. Furthermore, design reviews, i.e. marking important milestones in the development process of supplied products are as a rule made jointly by suppliers and customers in order to guarantee the accomplishment of project targets (Fig. 7). continuously. In the focal point of the requirements made by automobile manufacturers of their suppliers is quality competence. As our study has made evident, there are substantial differences between the companies in the various triad regions. While in Japan an excellent control over processes has evolved primarily, the best European and American companies convince through higher final customer competence.

Since the overall conditions in the various automobile markets are gaining in similarity, also the relevant success factors for automotive suppliers will become more uniform. This means that the companies from the various triad regions can and must learn from the strengths of the others in order to hold their own successfully in the market. For the Japanese this means that they will have to aim their sights more strongly on final customers, i.e. car purchasers, in order to differentiate from their competitors. The Americans and Europeans on the other hand will have to learn from the excellent process capabilities of the Japanese, to build up an effective KAIZEN as well as to improve integration of the value addition chain linking customers and suppliers.

\section{Summary}

The requirements made of the automotive suppliers industry grow 


\section{PRODUÇÃO}

Characteristics of The Automotive Industry In The Triade

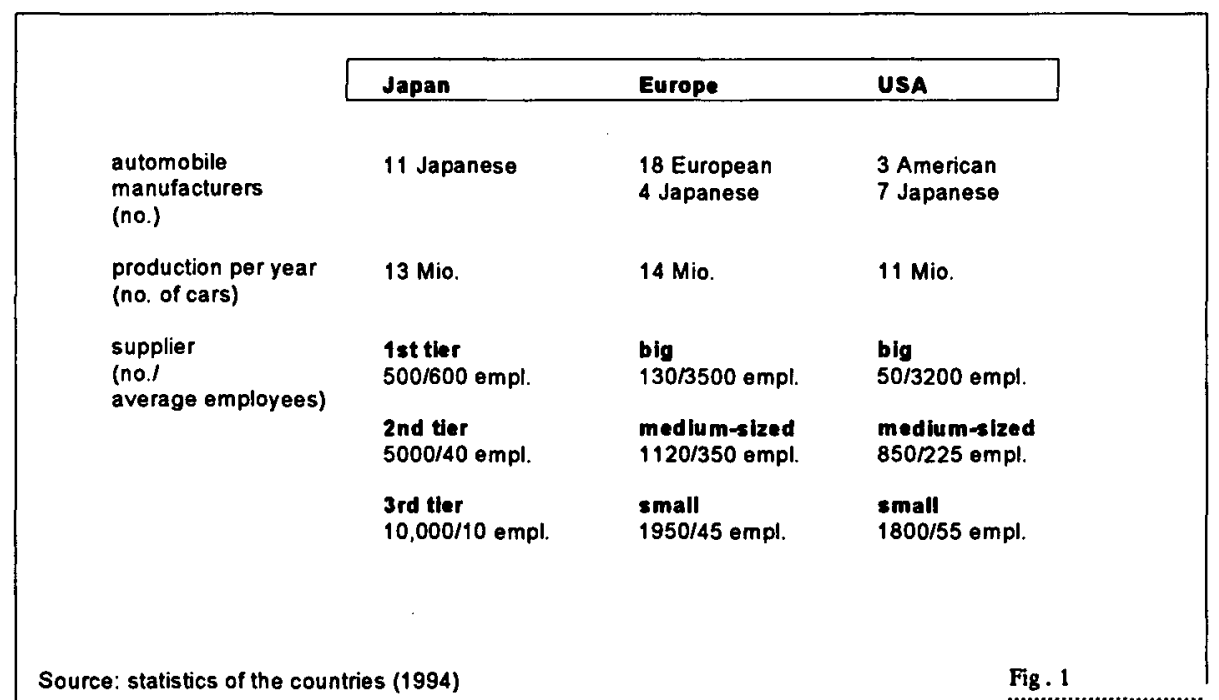

USA Has The Best Productivity Improvement

value added* per employee in 1,000 US\$

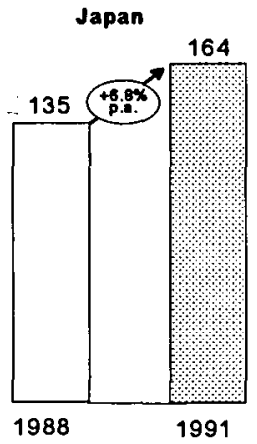

USA

Europe
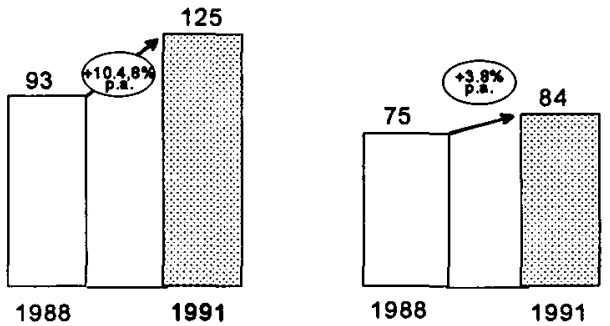

- turnover minus material costs 


\section{PRODUÇÃO}

Financing Of The R\&D - Effort Gets More Difficult

ज्ञात

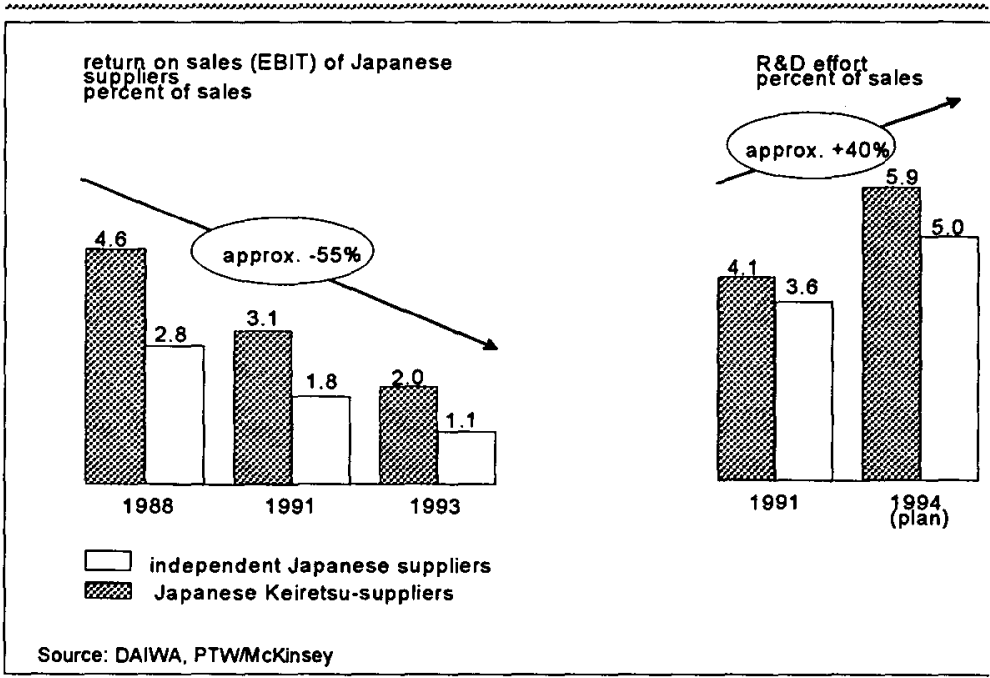

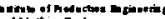

sales (EB|T) of Japanese percent of sales

independent Japanese suppliers

Japanese Keiretsu-suppliers
Fig. 3

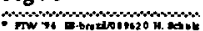

จำ

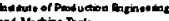

Buropean Companies Must Improve Quickly

(n)

development of internal scrap rate percent

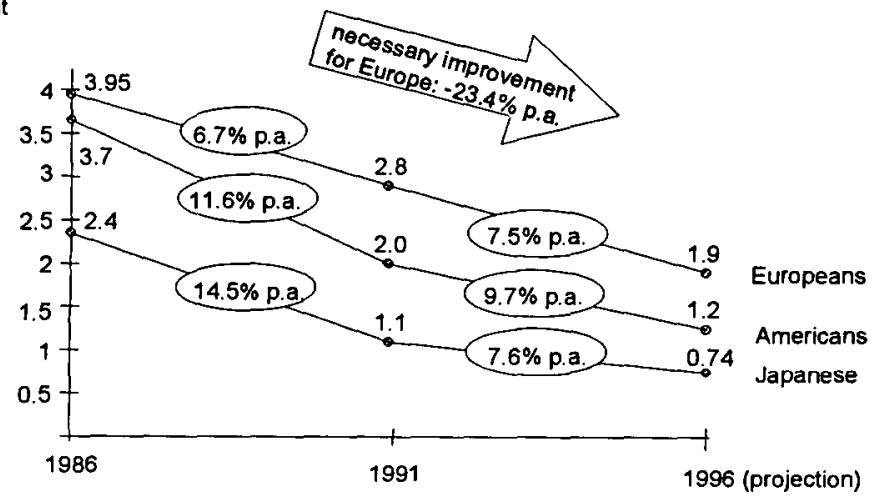




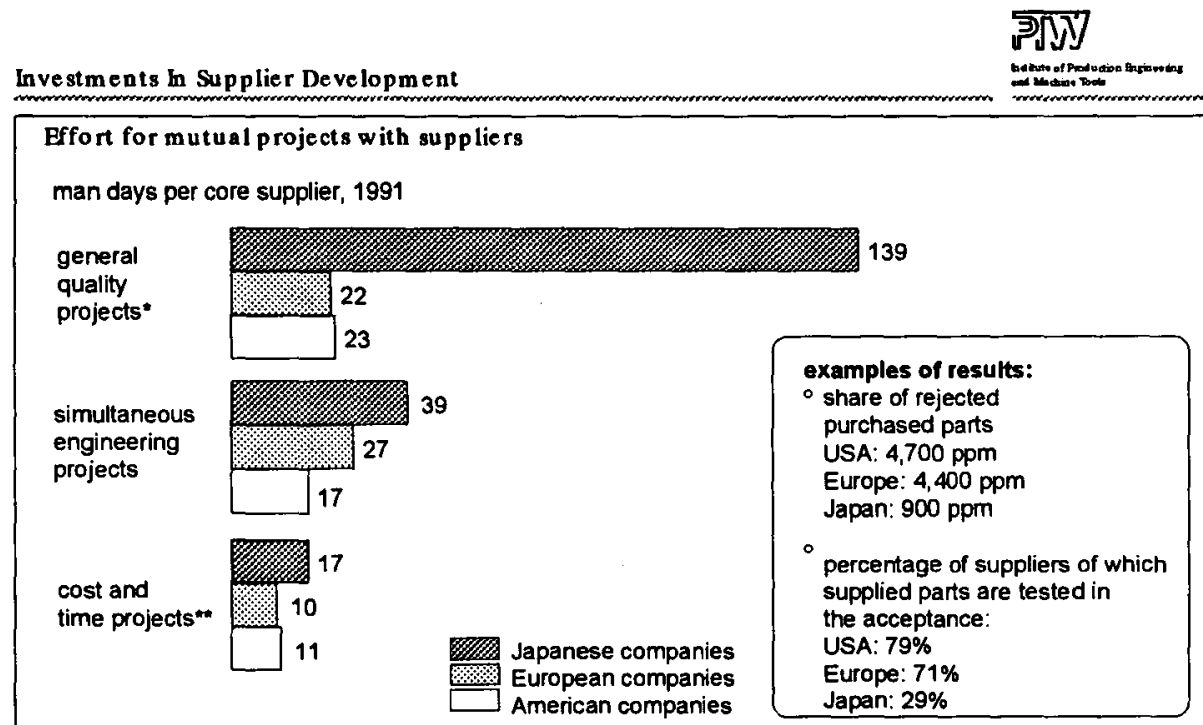

- production optimization, improvement of product quality, training QA-instruments

* improvement of on shedule production, throughput time, cost structures

Source: PTWMakinsey

Fig. 5

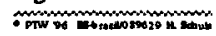

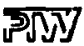

Close Cooperation With Customers During The Development Phase

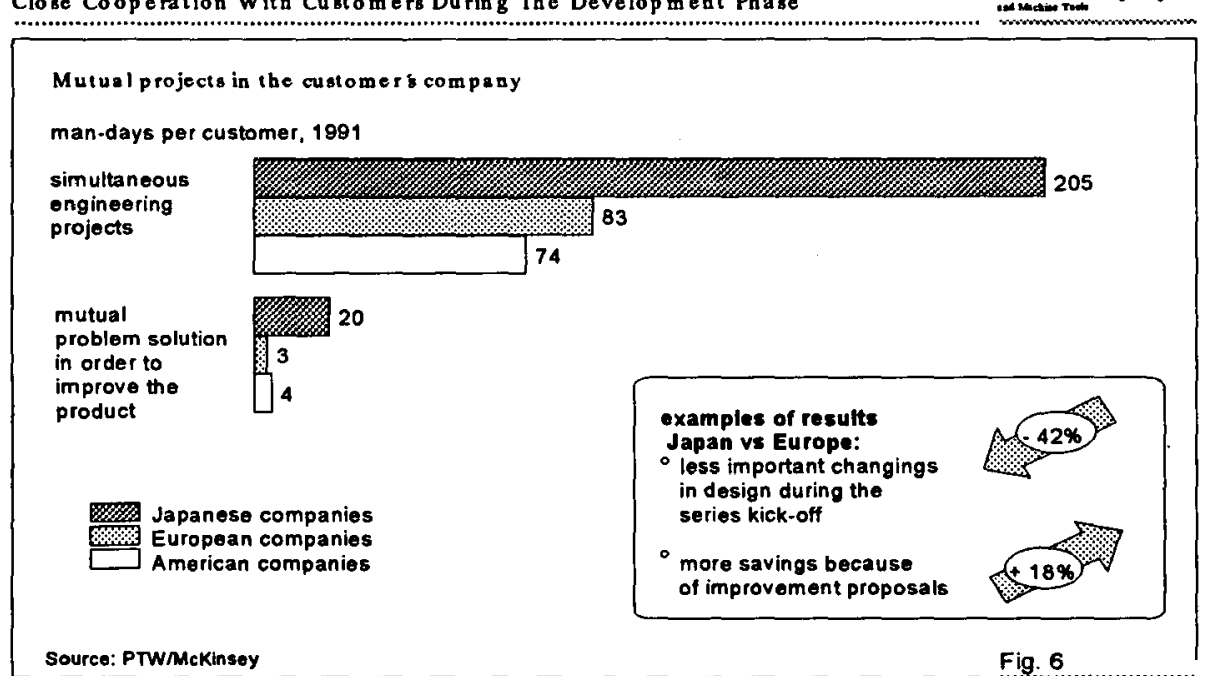


Application of QA instruments within R\&D department percent of companies

process FMEA

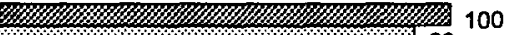
76

product FMEA

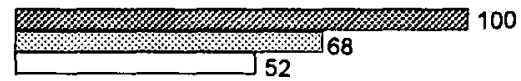

failure tree analysis (FTA)

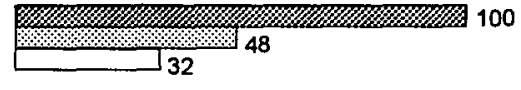

design review

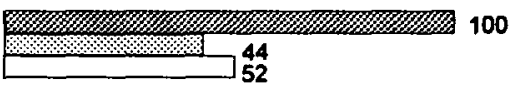

design of experiments (DOE)

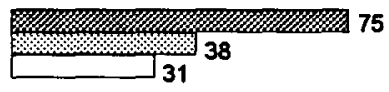

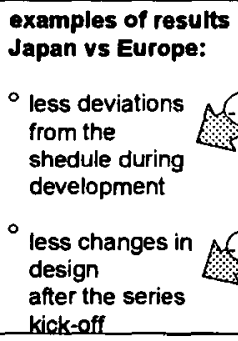

- less deviations from the shedule during development

- less changes in design after the series kick-off

Japanese companies

European companies

American companies

Fig. 7 